\title{
MOTION STUDY OF FOUR-ROW COTTON HARVESTER AND THE HITCH SYSTEM OF HARVESTING UNIT UNDER VERTICAL VIBRATIONS
}

\author{
AZIMOV B.M. ${ }^{1}$, KUBAEV S.T ${ }^{2}$, AHMEDOV SH.A ${ }^{3}$, YAKUBJANOVA D.K. ${ }^{4}$ \\ ${ }^{1}$ Scientific and Innovation Center of Information and Communication Technologies at Tashkent University of Information \\ Technologies, Tashkent, Uzbekistan \\ ${ }^{2}$ Tashkent University of Information Technologies, Tashkent, Uzbekistan \\ ${ }^{3}$ LLC Design Technological Center of Agricultural Machines (KTCSM) \\ ${ }^{4}$ Tashkent University of Information Technologies, Tashkent, Uzbekistan
}

\begin{abstract}
Equations of motion of the cotton harvesting machine (CHM) and the hitch system of the harvesting unit under vertical vibrations are considered in the paper. Mathematical models of the CHM MX-2.4 were developed based on the obtained equations of motion. The values of vertical vibrations of the CHM MX-2.4 when moving along a rough field were determined by solving mathematical model and conducting experimental studies.

KEYWORDS: Cotton Harvesting Machine, Hitch Mechanism, Mathematical Model, Control, Experimental Research
\end{abstract}

Received: Jun 05, 2020; Accepted: Jun 25, 2020; Published: Jul 30, 2020; Paper Id.: IJMPERDJUN2020524

\section{INTRODUCTION}

Productivity and agrotechnical indices of cotton harvesters are connected with the reliability of cotton harvesters and their working units under various motion conditions. Therefore, the development of the methods for scientifically sound design of cotton harvesting machines and the hitch systems of their operating units with the aim of improving them is an urgent task.

The manufactured two-row vertical-spindle cotton harvester CHM MX-2.4 is aggregated with a TTZ-LS $100 \mathrm{HC}$ tractor in a semi-hitch manner, the front steering wheels are dismantled, the unit is made according to a four-wheel design with two rear steering wheels.

The task of improving the design of a new generation of the four-row CHM is to enhance the functionality and basic technical characteristics [1-3,7,8]. One of the ways to solve the controllability problems of the four-row CHM is a mathematical modeling and experimental investigation of a machine under various motion conditions.

Mathematical Model of Vertical Vibrations of the Harvester Hitch System Under Various Motion Conditions

The construction of object-oriented mathematical models for complex technical systems of control is a complicated scientific and technical task, the evaluation of which is conducted mainly by a decision making person.

The whole difficulty of constructing such model lies in the fact that in order to obtain a solution, the model should be quite simple and at the same time it should reflect the essence of the problem so that the results obtained have real physical meaning.

In this regard, the requirements for a mathematical model of the dynamics of a cotton harvester with the 
hitch systems are determined by a set of tasks, the solution of which must provide the necessary information to assess its performance. When developing a mathematical model of vertical vibrations of the harvester hitch system under various motion conditions, it should be noted that the machine hydraulic system is functionally interconnected with its working system

In deriving the differential equations of the CHM rectilinear motion, a special place is taken by the reasonable assumptions. Assumptions should, on the one hand, ensure that the requirements for the mathematical model are met, and on the other, limit the number of simulated system parameters to the most necessary ones.

In view of the above and in accordance with the design scheme shown in Figure 1, a generalized mathematical model of the CHM MX-2.4 was developed in the form of Lagrange equations of the second kind under vertical vibrations in the process of moving along the roughness on the headland of a cotton field [1-6]:

$$
\begin{aligned}
& m_{M} \ddot{y}_{M}=F_{y}-b_{1}\left(\dot{y}_{M}-\dot{y}_{\text {кил }}\right)-c_{1}\left(y_{M}-y_{\text {кnл }}\right)-b_{2}\left(\dot{y}_{M}-\dot{y}_{\text {кnn }}\right)-c_{2}\left(y_{M}-y_{\text {кnn }}\right)- \\
& -b_{3}\left(\dot{y}_{M}-\dot{y}_{к 3 \Omega}\right)-c_{3}\left(y_{M}-y_{к 3 \Omega}\right)-b_{4}\left(\dot{y}_{M}-\dot{y}_{к 3 n}\right)-c_{4}\left(y_{M}-y_{к 3 \Omega}\right) \\
& m_{\kappa n л ~} \ddot{y}_{\kappa n л}=b_{1}\left(\dot{y}_{M}-\dot{y}_{\kappa n л}\right)+c_{1}\left(y_{M}-y_{\kappa n л}\right)-m_{\kappa n л} \frac{2 \pi^{2} V_{\kappa n л l}^{2}}{l_{5}^{2}} h_{n}\left(1-\cos \frac{2 \pi V_{\kappa n л}}{l_{5}} t\right) \\
& m_{\kappa n n} \ddot{y}_{\kappa n n}=b_{2}\left(\dot{y}_{M}-\dot{y}_{\kappa n n}\right)+c_{2}\left(y_{M}-y_{\kappa n n}\right)-m_{\kappa n n} \frac{2 \pi^{2} V_{\kappa n n}^{2}}{l_{5}^{2}} h_{n}\left(1-\cos \frac{2 \pi V_{k n n}}{l_{5}} t\right)
\end{aligned}
$$

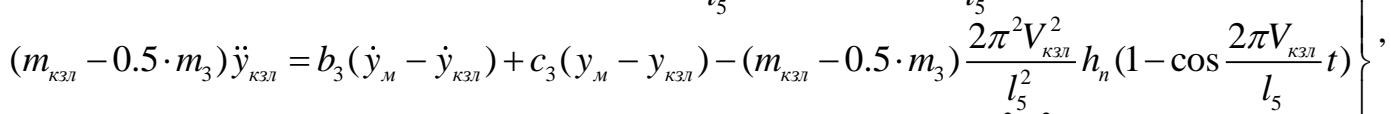

$$
\begin{aligned}
& \left(m_{\kappa з n}-0.5 \cdot m_{3}\right) \ddot{y}_{\kappa з n}=b_{4}\left(\dot{y}_{M}-\dot{y}_{к з n}\right)+c_{4}\left(y_{\mu}-y_{к з n}\right)-\left(m_{2}-0.5 \cdot m_{3}\right) \frac{2 \pi^{2} V_{\kappa 3 n}^{2}}{l_{5}^{2}} h_{n}\left(1-\cos \frac{2 \pi V_{\kappa з n}}{l_{5}} t\right) \\
& j_{z u} \ddot{\varphi}_{z u}=F_{2 u} \cdot l_{6}-b_{5}\left(\dot{\varphi}_{z u}-\dot{\varphi}_{8 K}\right)-c_{5}\left(\varphi_{z u}-\varphi_{8 K}\right)-l_{7} \cdot m_{a} \ddot{y}_{м} \\
& j_{6 \kappa} \ddot{\varphi}_{6 \kappa}=b_{5}\left(\dot{\varphi}_{z u}-\dot{\varphi}_{6 \kappa}\right)+c_{5}\left(\varphi_{z u}-\varphi_{6 \kappa}\right)-l_{7} \cdot m_{a} \ddot{y}_{M} \\
& m_{2 u} \ddot{y}_{2 u}=\frac{j_{2 u} \ddot{\varphi}_{2 u}}{l_{7}-l_{6}} \\
& m_{6 \kappa} \ddot{y}_{6 \kappa}=\frac{j_{6 \kappa} \ddot{\varphi}_{6 \kappa}}{l_{7}}
\end{aligned}
$$

where $b_{i}, c_{i}$ - are the coefficients of viscous resistance and tire stiffness of machine wheel, rocker shaft of the harvester hitch mechanism; $m_{i}$ is the mass distributed over the supports of the machine and the hitch mechanism of the harvester; $h_{n}$ is the height of the road roughness; $F_{2 u}$ is the force in the hydraulic cylinder of the hitch mechanism; ; $l_{l}, l_{2}, l_{3}$, $l_{4}$ and $l_{5}$ are the distances between supports and the roughness; $l_{6}$ and $l_{7}$ are the lengths of the levers for hitching the harvesting units; $j_{г u}$ and $j_{6 \kappa}$ are the moments of inertia of the levers connecting the hydraulic cylinder and the hitch system of the harvesters.

System (1) was solved using the numerical Runge-Kutta method [4, 6].

Computational and field experiments were carried out for the following parameter values under tire deflection $h_{u}=40 \mathrm{~mm}=0.04 \mathrm{~m}:$

the stiffness coefficient of the tire of the front left wheel $\mathrm{cl}=$ спл $=310241.25 \mathrm{~N} / \mathrm{m}$;

the stiffness coefficient of the tire of the front right wheel $c_{2}=c_{\text {III }}=310241.25 \mathrm{~N} / \mathrm{m}$;

the stiffness coefficient of the tire of the rear left wheel $c_{3}=c_{3 л}=639489.38 \mathrm{~N} / \mathrm{m}$; 
the stiffness coefficient of the tire of the rear right wheel $c_{4}=c_{3 n}=639489.38 \mathrm{~N} / \mathrm{m}$;

the stiffness coefficient of the rocker shaft $\mathrm{c}_{5}=\mathrm{c}_{\mathrm{BK}}=531458.28 \mathrm{Nm} / \mathrm{rad}$;

coefficient of viscous resistance of the tire of the front left wheel $b_{1}=b_{\text {II }}=45144.16 \mathrm{Nmf} / \mathrm{m}$;

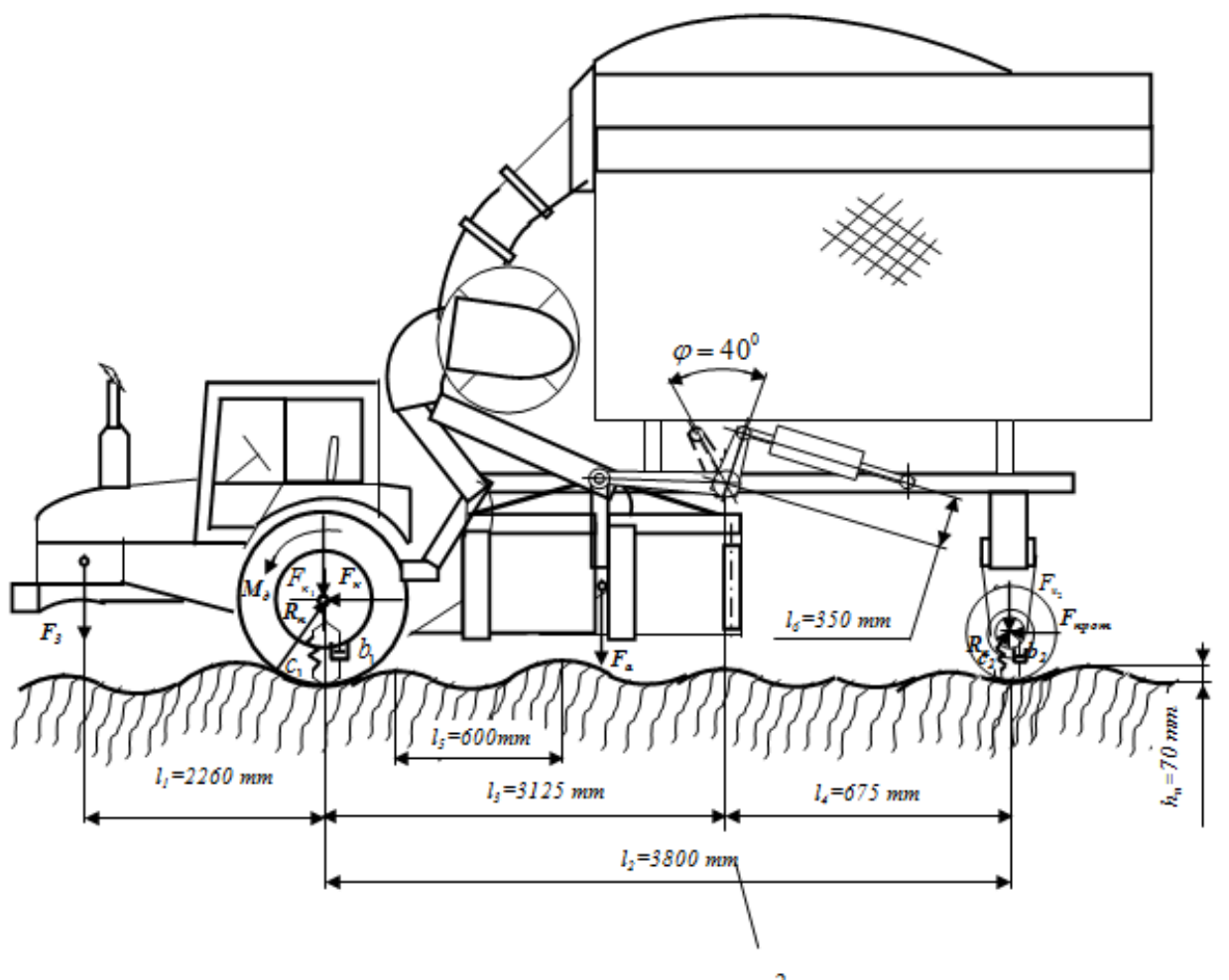

(a)

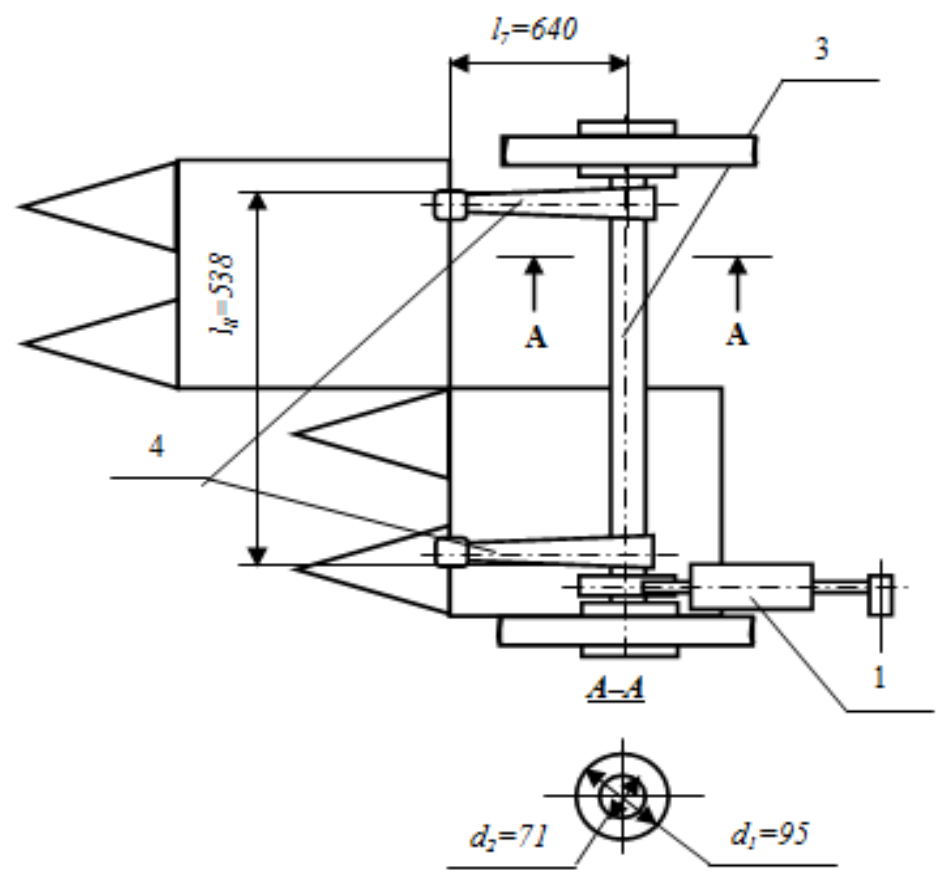

(b)

Figure 1: Settlement Scheme CHM MX-2.4 
a) - dynamic model MX-2.4; b) top view of the left block of the MX-2.4 harvester hitch mechanism: 1- a hydraulic cylinder; 2 - a lever for connecting the hydraulic cylinder; 3 - a rocker shaft; 4 - the levers for hitching the harvesting units; 5 -a harvesting unit.

coefficient of viscous resistance of the tire of the front right wheel $b_{2}=b_{п п}==45144.16 \mathrm{Nmf} / \mathrm{m}$;

coefficient of viscous resistance of the tire of the rear left wheel $b_{3}=b_{3 л}==93054.08 \mathrm{Nf} / \mathrm{m}$;

coefficient of viscous resistance of the tire of the rear right wheel $b_{4}=b_{3 n}=93054.08 \mathrm{Nf} / \mathrm{m}$;

coefficient of viscous resistance of the rocker shaft $b_{5}=b_{\text {вк }}=77334.137 \mathrm{Nmf} / \mathrm{m}$;

machine mass $\mathrm{m}_{\mathrm{M}}=7745 \mathrm{~kg}$; the mass of the front left wheel $\mathrm{m}_{\text {кпл }}=1265 \mathrm{~kg}$; the mass of the front right wheel $\mathrm{m}_{\text {кпп }}=1265 \mathrm{~kg}$; the mass of the rear left wheel $\mathrm{m}_{\text {кзл }}=2607.5 \mathrm{~kg}$; mass of the rear right wheel $\mathrm{m}_{\text {кзп }}=2607.5 \mathrm{~kg}$; engine mass $m_{3}=1200 \mathrm{~kg}$; the mass of the harvester unit $\mathrm{m}_{\mathrm{a}}=675 \mathrm{~kg}$; the moment of inertia of the hydraulic cylinder $j_{2 u}=552.96$ $\mathrm{Nmf}^{2}$; the moment of inertia of the rocker shaft $j_{\text {вк }}=276.48 \mathrm{Nmf}^{2}$; the radius of the rear wheels $\mathrm{r}_{\mathrm{K} 3}=0.785 \mathrm{~m}$; radius of front wheels $\mathrm{r}_{\text {кп }}=0.43 \mathrm{~m} ; h_{n}=0.07 \mathrm{~m} ; \mathrm{V}_{\mathrm{M}}=1.1 \mathrm{~m} / \mathrm{s} ; F_{y}=11550 \mathrm{~N} ; F_{y}=11550 \mathrm{~N}$.

\section{Experimental Studies of Four-Row Cotton Harvester Mx-2.4 Vibrations}

The aims of the tests are:

field measurement of vibrations of a four-row cotton harvester and hitch systems of MX-2.4 harvesting units;

a comparative analysis of the results of theoretical and experimental studies of vibrations of a four-row cotton harvester and hitch systems of harvesting units MX-2.4;

In testing the accelerometers were installed on the front and rear axles, as well as on the levers of the rocker shaft of the hitch system of MX-2.4 harvesters.

The measurements were carried out as follows.

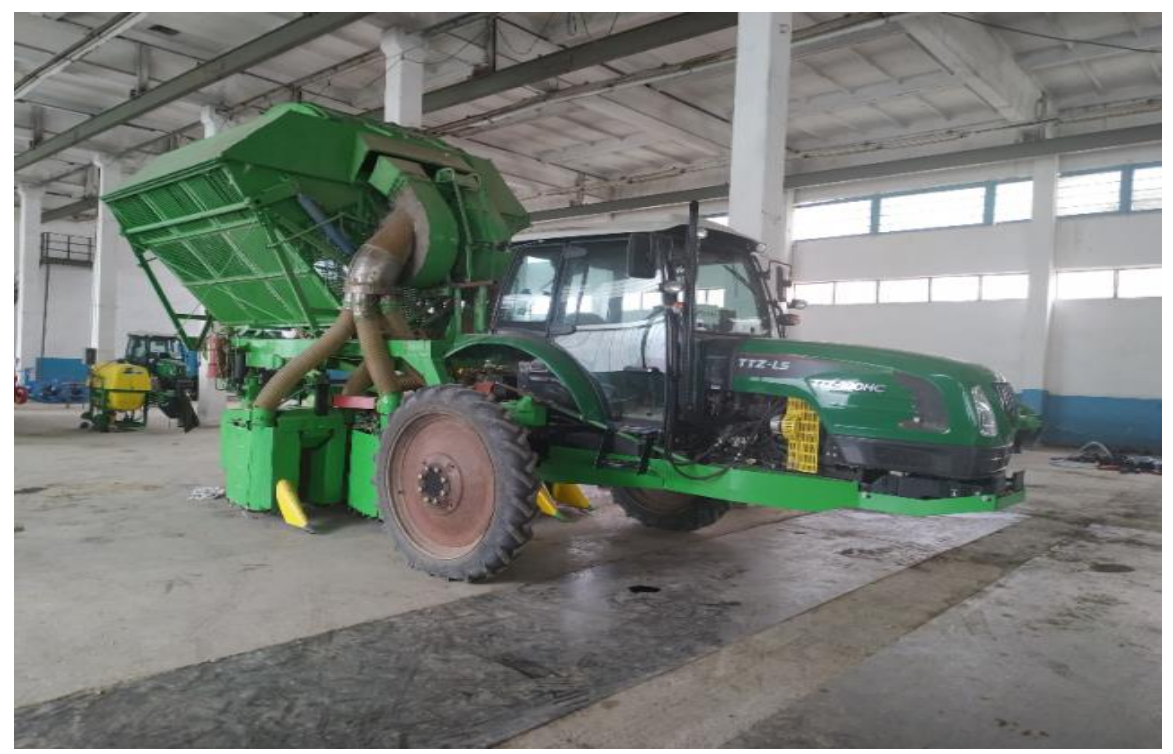

Figure 2: Location of Measuring Points: ) 4-Row Cotton Harvester MX-2.4. 


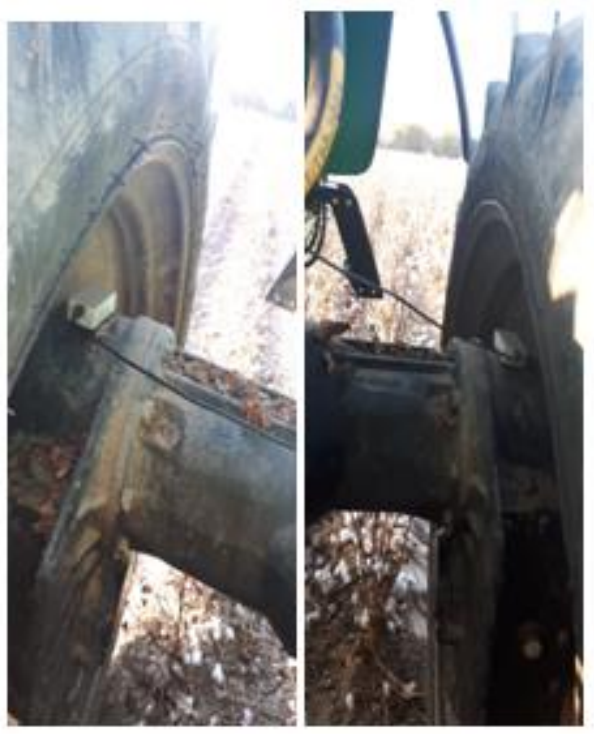

(a)
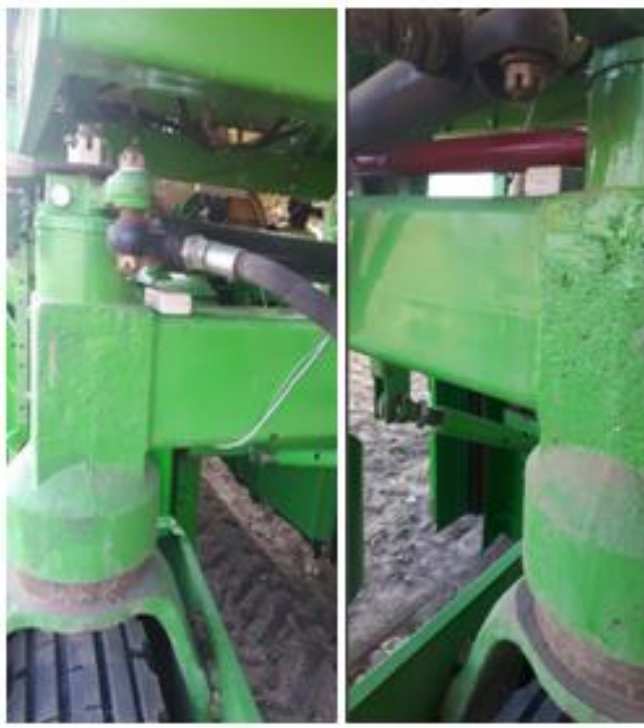

(b)

Figure 3: Location of Measuring Points (a) Installation of Accelerometers on the Front Axle of the CHM; (b) Installation of Accelerometers on the Rear Axle of the CHM.

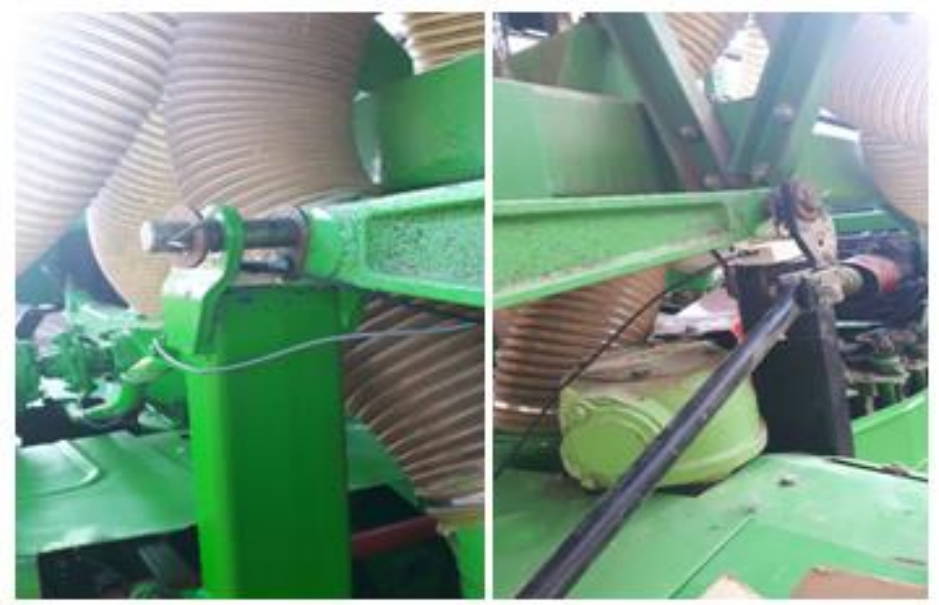

Figure 4: Location of Measuring Points: Installation of Accelerometers on the Levers of the CHM Rocker Shaft.

Measurements of the CHM vibrations were made by the ADXL345 accelerometer - it is a small (micro) powerful triaxial accelerometer of high resolution (13 bits). The measuring range of the position varies up to $\pm 16 \mathrm{~g}$. The measurement result is given in the form of 16-digit numbers in an additional code and through digital interfaces SPI / I2C.

The ADXL345 accelerometer is ideal for use on mobile devices - it measures static acceleration (caused by gravity) in deflection problems, or dynamic acceleration caused by displacement or shock. The declared high resolution of the accelerometer (4·10-3 g/LSB) allows accurate tracking the change in deviation of less than $1.0^{\circ}$. The sensor's low power mode enables intelligent system power management.

\section{Characteristics}

- accelerometer power supply: 3-5V 
- $\quad$ supported interfaces: I2C, SPI

- resolution: $13 \mathrm{bit}, 4 \mathrm{mg} / \mathrm{LSB}$

- $\quad$ measuring range: $+/-16 \mathrm{~g}$

- dimensions: 20x15mm

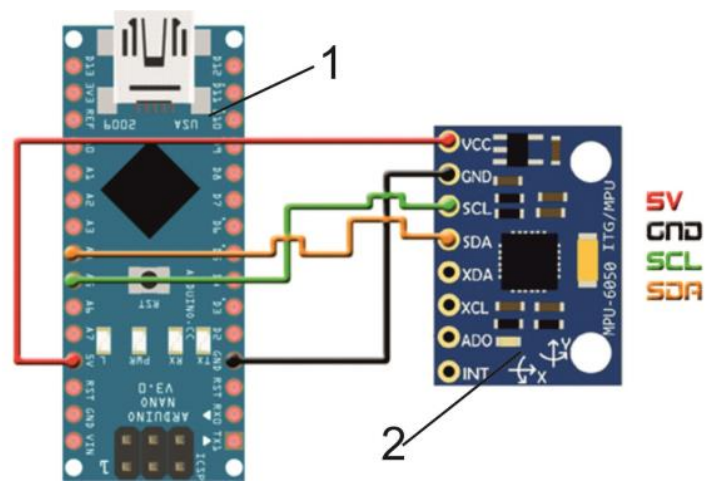

Figure 5: Connection Diagram

- Arduino nano microcontroller

- Accelerometer ADXL345 Arduino code for reading data from the sensor.

The test results are shown in table 1 .

Table 1: The Values of Operation Parameters of the CHM MX-2.4 Under Vertical Vibrations at $H_{m}=40$ $\mathrm{Mm}, \mathrm{H}_{n}=70 \mathrm{Mm}, \ddot{y}_{i}=\ddot{z}_{i}$

\begin{tabular}{|c|c|c|c|c|c|c|c|c|c|c|}
\hline & 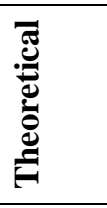 & - & & - & 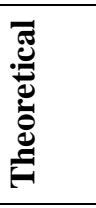 & - & 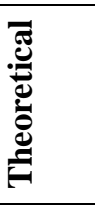 & - & & 胥 \\
\hline $\begin{array}{c}\mathrm{T}, \\
\mathrm{s}\end{array}$ & $\begin{array}{l}\ddot{z}_{\kappa n л}, \\
\mathrm{~m} / \mathrm{s}^{2}\end{array}$ & $\begin{array}{c}\ddot{z}_{\kappa n \pi}, \\
\mathrm{m} / \mathrm{s}^{2}\end{array}$ & $\begin{array}{l}\ddot{z}_{\kappa n n}, \\
\mathrm{~m} / \mathrm{s}^{2}\end{array}$ & $\begin{array}{c}\ddot{z}_{\kappa n n}, \\
\mathrm{~m} / \mathrm{s}^{2}\end{array}$ & $\begin{array}{l}\ddot{z}_{к з л}, \\
\mathrm{~m} / \mathrm{s}^{2}\end{array}$ & $\begin{array}{l}\ddot{z}_{к з л}, \\
\mathrm{~m} / \mathrm{s}^{2}\end{array}$ & $\begin{array}{l}\ddot{z}_{\kappa з n}, \\
\mathrm{~m} / \mathrm{s}^{2}\end{array}$ & $\begin{array}{c}\ddot{z}_{\kappa з n} \\
\mathrm{~m} / \mathrm{s}^{2}\end{array}$ & $\begin{array}{l}\ddot{z}_{\text {BKl}}, \\
\mathrm{m} / \mathrm{s}^{2}\end{array}$ & $\begin{array}{c}\ddot{z}_{\text {в }}, \\
\mathrm{m} / \mathrm{s}^{2}\end{array}$ \\
\hline 1 & 2 & 3 & 4 & 5 & 6 & 7 & 8 & 9 & 10 & 11 \\
\hline 0 & 0 & 0 & 0 & 0 & 0 & 0 & 0 & 0 & 0 & 0 \\
\hline 0.1 & 0.16 & 0.18 & 0.16 & 0.17 & 0.14 & 0.18 & 0.14 & 0.19 & 0.224 & 0.20 \\
\hline 0.2 & 0.14 & 0.26 & 0.14 & 0.18 & 0.12 & 0.17 & 0.12 & 0.17 & 0.24 & 0.20 \\
\hline 0.3 & 0.11 & 0.21 & 0.11 & 0.19 & 0.1 & 0.21 & 0.1 & 0.18 & 0.244 & 0.21 \\
\hline 0.4 & 0.06 & 0.16 & 0.06 & 0.18 & 0.06 & 0.18 & 0.06 & 0.16 & 0.23 & 0.22 \\
\hline 0.5 & 0.04 & 0.14 & 0.04 & 0.17 & 0.04 & 0.19 & 0.04 & 0.19 & 0.195 & 0.19 \\
\hline 0.6 & 0.15 & 0.16 & 0.15 & 0.20 & 0.15 & 0.17 & 0.15 & 0.21 & 0.16 & 0.19 \\
\hline 0.7 & 0.18 & 0.14 & 0.18 & 0.21 & 0.18 & 0.19 & 0.18 & 0.2 & 0.14 & 0.15 \\
\hline 0.8 & 0.06 & 0.10 & 0.06 & 0.19 & 0.07 & 0.1 & 0.07 & 0.2 & 0.16 & 0.17 \\
\hline 0.9 & 0.1 & 0.07 & 0.1 & 0.21 & 0.1 & 0.15 & 0.1 & 0.16 & 0.25 & 0.20 \\
\hline 1 & 0.14 & 0.17 & 0.14 & 0.21 & 0.12 & 0.12 & 0.12 & 0.19 & 0.2 & 0.19 \\
\hline
\end{tabular}




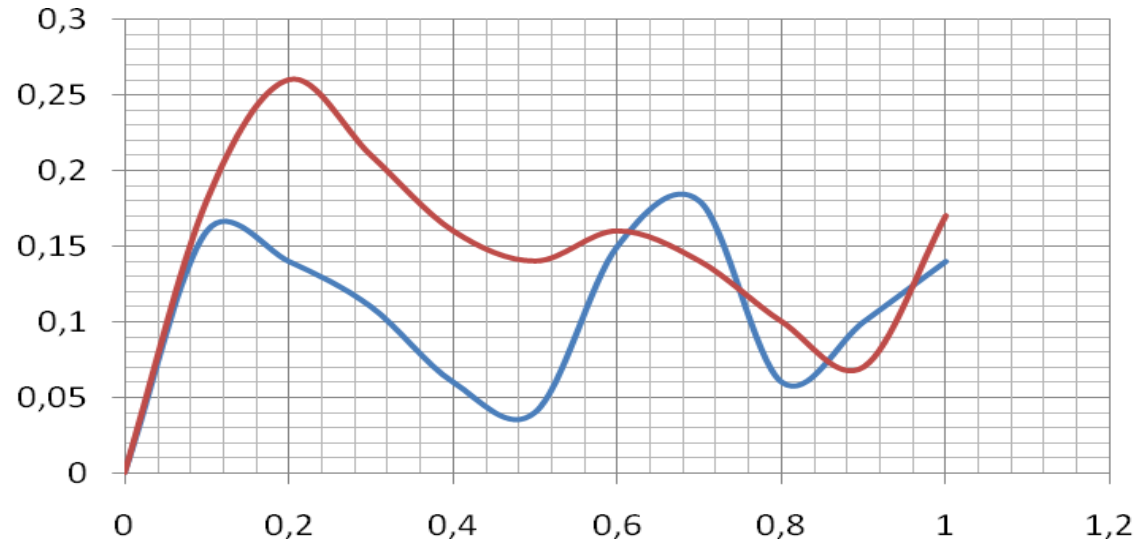

(a)

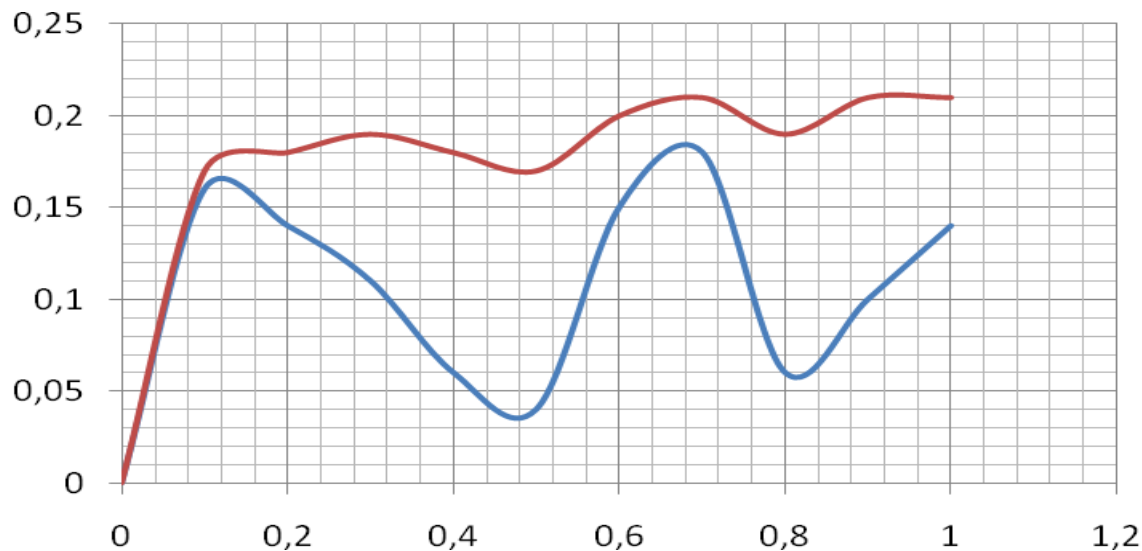

(b)

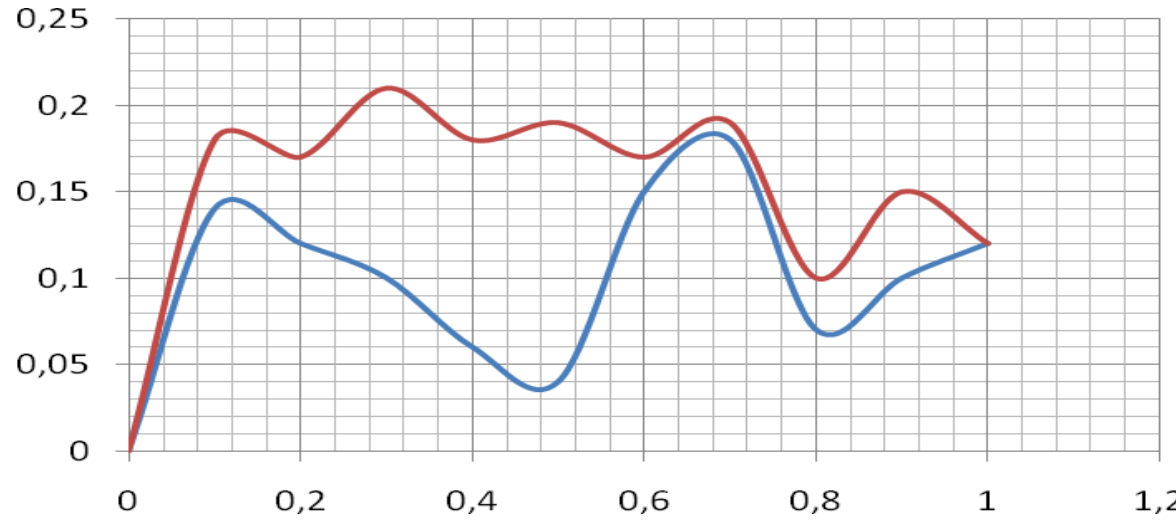

(c)

theoretical,

(c)

$$
\text { experimental }
$$

Figure 6: Graphs of Theoretical and Experimental Studies of the CHM MX-2.4 Vertical Vibrations: (a) Front Left Wheel; (b) Front Right Wheel; (c) Rear Left Wheel.

\section{CONCLUSIONS}

- Experimental values of the CHM vibrations are in satisfactory agreement with the theoretical values.

- Thus, the steadiness of machine motion depends on the mass and operating parameters, the values of which are determined by numerical solution of system (1) with a variation of motion parameters and design parameters $b$, $c$, 
$m_{i}, j_{i}$ for given road roughness.

- The developed mathematical model of vertical vibrations can significantly reduce the time for experimental refinement of new designs of cotton harvesting machines.

\section{REFERENCES}

1. Azimov B.M., Yakubjanova D.K. Imitation modeling and calculation of the parameters of lateral forces components of guide wheels of cotton-picker MH-1.8/ International journal of advanced research in science, engineering and technology. Vol. 5, 2018. Is. 1. P. 5024-5032.

2. Azimov B. M. and Yakubjanova D. K. Modeling and optimal control of motion of cotton harvesting machines MX-1.8 and hitching systems of picking apparatus under vertical oscillations // Journal of Physics: Conference Series, 2019. DOI: 10.1088/1742-6596/1210/1/012004.

3. Azimov B.M., Sulyukova L.F., Azimov M.B. Modeling and Research of the Controllability of Wheeled Tractors// International Journal of Innovative Technology and Exploring Engineering (IJITEE) ISSN: 2278-3075, Volume-9 Issue-1, November 2019. P.2344-2351.

4. Afanasyev V.N., Kolmanovsky V. B., Nosov V. R. Mathematical theory of designing control systems. M.: Vysshaya shkola, 1989. P. $162-163$.

5. Kaur, Amandeep, Vijay Kumar, and Dhawan AK. "Population Monitoring of Cotton Bollworm Moth with Sex Pheromones in Punjab, India." International Journal of Agricultural Science and Research (IJASR) 6.3 (2016).

6. Babashev K.A., Azimov M.B. Mathematical modeling and control of testing processes of wheel vehicles // Proceedings of the XVIII International Scientific and Methodological Conference "Computer Science: Problems, Methodology, Technologies". Volume 5. Voronezh, Scientific Research Publications Publishing House, “Wellborn” LLC. 2018. -P. 108-113.

7. BARSHA, UMMEY HANI, et al. "Investigation on physical properties of jute cotton (jutton) blended fabric." International Journal of Textile and Fashion Technology (IJTFT) at https://www. academia. edu/37099922/INVESTIGATION _ON_PHYSICAL_PROPERTIES_OF_JUTE_COTTON_JUTTON_BLE NDED_FABRIC (2018): 1-8.

8. Vasiliev F. P. (1988). Numerical methods for solving extreme problems. Moscow: Nauka, (pp. 421-485).

9. Guskov V.V. et al. (1988). Tractors: Theory. Moscow: Mechanical Engineering, (pp. 33-35).

10. GN, Motaka, et al. "Study on Variability in Field Experiments of Cotton Crop (Bhal and Coastal Zone)." International Journal of Agricultural Science and Research (IJASR) 6.3 (2016).

11. Mrunalini, A., D. Esther, and J. Deepika. "Characterization of drudgery in cotton production systems." International Journal of Agricultural Science and Research (IJASR) 5.2 (2015): 147-152.

12. Smirnov G.A. (1990). Motion theory of wheel vehicles. Moscow.: Mechanical Engineering, (pp.145-230). 


\section{AUTHORS PROFILE}

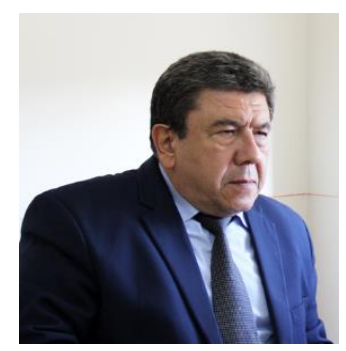

Azimov Bakhtiyor Magrupovich - Doctor of Technical Sciences, Senior Researcher.

Head of the Laboratory "Management in Technical Systems", the field of study of which is mathematical modeling, diagnosis and optimal control of complex technical and technological systems in mechanical engineering. Under his leadership, in recent years, mathematical models and an algorithm for assessing the dynamic stability of the movement of the cotton-picking machine under horizontal and vertical vibrations have been developed; Mayer's task is formulated for optimal control of the hinged system of the cotton picker; mathematical models of a test bench for testing a four-wheel universal row-crop tractor equipped with a rear axle with steplessly adjustable clearance have been developed; An algorithm for optimal control of a test bench for testing a four-wheel universal row-crop tractor equipped with a rear axle with stepless adjustable clearance has been developed.

Executive Secretary of the Uzbek journal "Problems of Informatics and Energy" of the Academy of Sciences of the Republic of Uzbekistan.

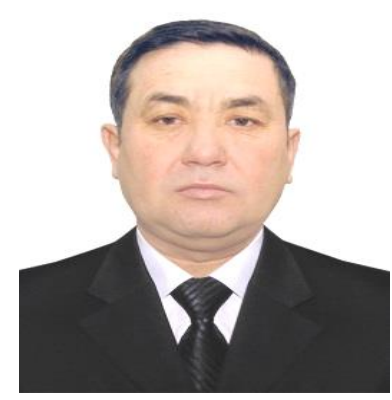

Kubaev Saydazim Tashbaevich - Candidate of Technical Sciences, Associate Professor. ST Kubaev published 103 scientific and methodical works, including 85 scientific, 1 monograph, 15 educational and methodical works, 2 computer programs. ST Kubaev supervises the pre-graduation work of graduates of bachelor's and master's specialties. He is currently conducting research on "Methods and algorithms for analyzing the controllability and stability of technological machines" and involves young professionals. 


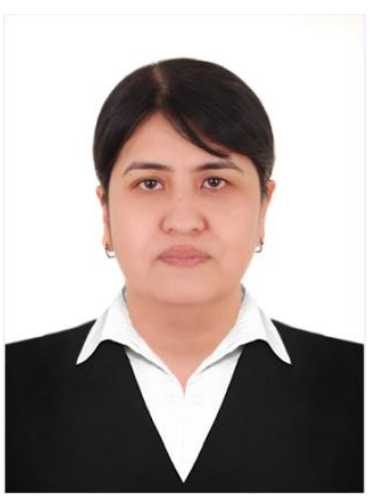

Yakubjanova Dilfuza Kodirovna - Doctor of Philosophy (PhD) in Technical Sciences. He defended his PhD dissertation on "Models of motion and control algorithms of suspension systems of machine-tractor units" in "System Analysis, Management and Information Processing". Area research mathematical modeling, diagnostics and optimal management of complex technical and technological systems in machine building. On the subject of scientific research published 30 scientific works, and also received 3 testimonials on the registration of software products for EVM.

Head of the Samarkand branch of the Tashkent University of Information Technology.

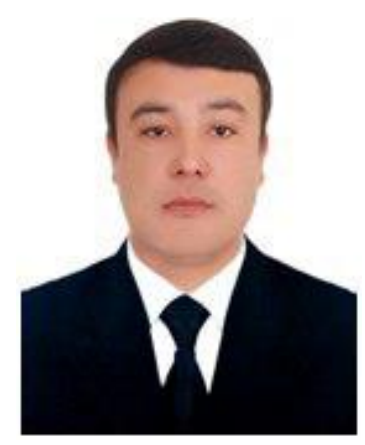

Ahmedov Sherzodbek, Ph. D (Mehanical engineering) - general director

of LLC Design And Technology Center of Agricultural Machinery. Research interests: modernization of agricultural machinery, increase of agrotechnical passability of universal-tilled tractors, introduction of smart technology in agricultural engineering. 